\title{
Análise teórica dos conceitos: Riscos Socioambientais, Vulnerabilidade e Suscetibilidade.
}

\author{
Theoretical analysis of the terms: Socioenvironmental Risks, Vulnerability and \\ Susceptibility.
}

GIRÃO ${ }^{1}$, I. R. F.; RABELO ${ }^{2}$, D. R.; ZANELLA ${ }^{3}$, M. E.

italorgirao@gmail.com;

\begin{abstract}
Resumo
Considerando o conceito de risco e partindo da forma como o homem se organiza e ocupa o espaço, entende-se que a situação de vulnerabilidade e a suscetibilidade estão postas nas diversas realidades, sendo que as características naturais e as condições sociais e econômicas constituem-se elementos variáveis que influenciam na maior ou menor condição dos mesmos. Para realização da determinação dos riscos socioambientais, consolida-se como fundamental a revisão bibliográfica dos conceitos, que, por sua vez, tiveram seu entendimento resignificado nas últimas décadas. Este trabalho propõe-se apresentar a revisão conceitual dos termos expostos no título, a fim de possibilitar um material que sirva como base para o avanço de programas e projetos associados à prevenção de desastres. Dessa forma, os resultados apontam um avanço no estudo de fontes bibliográficas sobre a temática em questão.
\end{abstract}

Palavras-chave: Revisão conceitual; Desastres; Sociedade e meio ambiente.

\begin{abstract}
Considering the concept of risk and starting from the way man organizes and occupies the space, it is understood that the situation of vulnerability and susceptibility are placed in the different realities, being that the natural characteristics and the social and economic conditions constitute variable elements that influence in the greater or lesser condition of the same. To carry out the determination of socio-environmental risks, the bibliographical revision of the concepts is consolidated as fundamental, which, in turn, had its understanding resignified in the last decades. This work proposes to present the conceptual review of the words presented in the title, in order to make possible a material that serves as a basis for the advance of programs and projects associated to disaster prevention. Thus, the results indicate an advance in the study of bibliographic sources on the subject in question.
\end{abstract}

Keywords: Conceptual review; Disasters; Society and environmental.

\section{INTRODUÇÃ̃O}

As atividades antrópicas, responsáveis pelas diversas modificações do espaço físico natural, necessitam de controle e atenção, quando levamos em consideração o seu potencial de impacto. Para reduzir os impactos negativos à natureza, sobretudo àqueles que possuem alta capacidade de degradação, faz-se importante ações de avaliação e mitigação ambiental. A degradação ambiental é o pilar dos problemas ambientais contemporâneos, especialmente pela atual condição de transformação do espaço físico-natural, num contexto social de desigualdade econômica e social. 
Outrossim, fatores socioeconômicos geram injustiça social. Concentração da renda e desordem na ocupação (sobretudo em desacordo com as normas de proteção ambiental e de seguridade sanitária) promovem maior exposição ao risco.

Em relação à onipresença dos riscos, sabe-se que o mesmo é inerente à existência da sociedade. Porém é comprovado que a maior exposição aos riscos é diretamente proporcional às condições de fragilidade físico-natural e vulnerabilidade. Ou como afirma Tricart (1977), é o maior ou menor estágio de estabilidade ou instabilidade dos fatores abióticos, frente às modificações geradas pela morfopedogênese e fitosucessão atuantes nas unidades ecodinâmicas, que possibilitam compreender os riscos e a vulnerabilidade.

Observa-se, portanto, que os riscos são existentes quando há um conjunto de variáveis naturais e sociais, que culminam na ocupação irregular, em ambientes cujas condições físiconaturais tendem ao frágil.

A vulnerabilidade está posta quando há um conjunto de fatores naturais e sociais específicos que fomentam a suscetibilidade ao risco. A hipótese deste trabalho é que o uso e a ocupação inadequados do solo, fomentado pelas características de vulnerabilidade e fragilidade geomorfológica, provoca a existência de áreas de risco socioambiental.

Nesse contexto, degradação, vulnerabilidade, suscetibilidade e riscos são conceitos associáveis e particulares entre si e importantes para a construção de uma reflexão sobre prevenção de desastres.

\section{METODOLOGIA}

A construção de um debate sobre modelos de desenvolvimento socioambiental requer a indagação sobre a forma de organização socioespacial do homem em sociedade, a partir da observação das formas de uso e ocupação do espaço. Espaço esse que, por sua vez, é constituído de formas diferentes e particularidades naturais complexas e diversas.

A interação entre os diversos fatores geomorfológicos incide sobre a realidade, consolidando condições de maior ou menor vulnerabilidade social e suscetibilidade aos riscos geomorfológicos.

A vulnerabilidade é a condição da sociedade frente às características do ambiente, reflexo das variáveis múltiplas (renda, habitação, educação etc.) que a mantém mais ou menos vulnerável. Zanella et. al. (2013), afirma que

As condições culturais, étnicas, políticas, econômicas, educacionais, sociais e de saúde vão tornar as pessoas e os grupos sociais mais ou menos vulneráveis, ou seja, refletem na capacidade de enfrentar, superar ou minimizar as dificuldades e 
aproveitar as oportunidades para melhorar sua situação de bem-estar (ZANELLA Et. Al., 2013, p. 320).

A suscetibilidade é o quão provável um determinado fenômeno pode ocorrer independente dos fatores sociais, mas tendo a sociedade como elemento de interferência que acelera ou retarda. Dentro dessa perspectiva, o semiárido é suscetível às secas, as planícies de inundação às inundações e as áreas de elevação topográfica aos movimentos de massa. A ação humana atua como ferramenta de modificação da dinâmica natural, acelerando-a ou retardandoa.

Outro ponto é que a suscetibilidade é específica a um fenômeno. Assim, as características do meio podem o tornar mais vulnerável aos movimentos de massa e menos as inundações, por exemplo.

Uma área de estudo necessariamente possui características naturais que são reflexo dos elementos dominantes no ato de sua gênese, ou mesmo do processo de sua formação, modelagem e transformação. Dentro de um discurso exclusivamente ambiental, diagnosticar uma área significa descrever suas particularidades e entender o processo que resultou as mesmas. Saber diferenciar os ambientes naturais possibilita comparar e estipular quais são mais frágeis e/ou instáveis que outros. É natural encontrar ambientes que ainda estão em processo de formação ou cujas características apontam para uma necessidade de não intervenção. Dessa forma, a suscetibilidade é um importante conceito de discussão.

Ao tratar-se de meio ambiente, separar a vertente humana do natural consolida-se como um erro grosseiro. A sociedade, enquanto principal agente transformador da natureza, pode produzir condições diversas de instabilidade e fragilidade, gerando risco, caso alguém seja afetado. Considerando que a instabilidade do meio pode existir independente do uso humano, refletimos que o uso e ocupação antrópica é capaz de acentuar e gerar maior suscetibilidade e o consequente risco. Dessa forma, os conceitos de vulnerabilidade e fragilidade são referências positivas para a realização de planejamentos ambientais, uma vez que a condição de suscetibilidade é maior ou menor conforme as características do ambiente, das condições socioeconômicas e da forma de uso e ocupação do meio.

A forma como a sociedade gera morfogênese está intimamente relacionada à forma como o homem ocupa o espaço.

Nesse debate, não se pode deixar de lado o conceito de degradação ambiental, como um fator exclusivamente antrópico, bem como a fragilidade do ambiente natural, dadas suas características naturais. Degradação ambiental aqui é entendida como a condição de prejuízo ao meio ambiente gerado, estritamente, pela sociedade. A degradação ambiental esta associada à 
perda das características de qualidade, mediante uma alteração adversa. Essa é, inclusive, a definição legal trazida pela Política Nacional de Meio Ambiente, estabelecida pela Lei 6.938, de 31 de agosto de 1981, que afirma: "degradação da qualidade ambiental, [é] a alteração adversa das características do meio ambiente" (BRASIL, Lei 6.938, 1981).

Para tornar completa a discussão, incorpora-se novas questões: i) como está a condição social e econômica do homem levado a causar degradação ambiental? ii) Essa degradação aumenta a suscetibilidade ao movimento de massa em áreas de elevação? Os riscos estão associados a que tipos de uso e ocupação?

Esse debate é oportuno e revela uma linha de pesquisa interessante. Considerando uma área de elevação, têm-se a hipótese de que o uso e a ocupação inadequado do solo provoca a existência de riscos geomorfológicos. A suscetibilidade ao movimento de massa, associado à vulnerabilidade socioeconômica, gera riscos socioambientais às comunidades e ao meio ambiente.

A sistemática utilizada para elaboração procedimental de construção do presente artigo seguiu a linha de pesquisa utilizada por Santos (2015), ao fomentar em sua pesquisa um roteiro que perpassa três fases de trabalho importantes: a) fase analítica; b) fase sintética; e, c) fase integrativa, numa perspectiva de análise sistêmica do meio ambiente e abordagem holística da realidade.

Objetivamente, a sistemática compreende (cf. SANTOS, 2015):

a) a fase analítica: que envolve a revisão bibliográfica dos termos alusivos aos conceitos ora trabalhados.

b) a fase sintética: onde foi desenvolvida discussão sobre as definições apresentadas pelos autores. Nessa etapa, ocorre a associação e integração das informações obtidas.

c) a fase integrativa: onde visa-se a obtenção de resultados condizentes com as abordagens adotadas, resultantes da complexidade de informações, fiéis a complexa realidade.

Dessa forma, propõe-se uma revisão conceitual e um debate sobre os termos expostos no título do trabalho em epígrafe, como uma forma de possibilitar uma revisão bibliográfica para a construção de uma geografia dos riscos.

\section{RESULTADOS E DISCUSSÃO}

Ao se falar de risco, é inevitável dar-se uma conotação negativa, prevalecendo o aspecto do ruim que pode acontecer. Assim, termos como: "risco de enriquecer" ou "risco de vitória", 
são expressões pouco ou não usadas. Entende-se que é usual tal associação Pelo fato de o conceito ser utilizado, desde antigamente, para indicar prejuízo.

O conceito de risco está relacionado ao sentido de imprevisibilidade ou a probabilidade de algo acontecer. Porém, a constante associação ao conceito de perigo, torna o risco um elemento de imprevisibilidade relacionado à exposição ao dano, ao ruim, ao severo.

Aurélio Buarque de Holanda Ferreira, cujo dicionário registra o termo Risco como sendo: exposição ao Perigo; inconveniente. (DICIONÁRIO AURÉLIO, 2016).

Diversas interpretações e designações, bem como os variados trabalhos insurgentes relacionados ao conceito, tem favorecido um maior aprofundamento sobre a temática. Tais recentes trabalhos não podem, entretanto, ser considerados pioneiros, haja vista que desde a Antiga Babilônia já haviam assessores profissionais para a análise de riscos, especialmente os ambientais (AUGUSTO FILHO, 2001). Já para Veyret, o termo risco data desde o Renascimento italiano, valorizando-se posteriormente em outros países, dado o aumento da demanda por segurança associada à necessidade de aumento da qualidade de vida (VEYRET, 2007).

Ou seja, não é de hoje que há preocupação do homem com o conhecimento e o domínio do conceito de risco. Isso significa que o arcabouço teórico para definição do termo é amplo, possibilitando uma variedade de fontes de consulta.

Há várias maneiras de definir os conceitos de risco [...], devido às diversas áreas de conhecimento que fazem uso deles, porém, a abordagem dá-se através de perspectivas diferenciadas. [...] o risco como conceito parte do discurso linguístico, tem-se constituído na trajetória histórica e cultural das sociedades e deve ser sempre pensado como processo e não como variável em si (JANCZURA, 2012, p. 302).

Isso deve ser considerado positivo, mas em termos de construção de uma linha de definição conceitual e epistemológica, as diferentes traduções e definições podem gerar linhas de desentendimento para uma apropriação mais ampla (MENEZES JÚNIOR; SILVA, 2016).

\footnotetext{
A noção de risco é complexa. Discute-se a origem do termo "risco", presente em todas as línguas europeias (inglês: risk, italiano: rischio, espanhol: riza). Ela pode ser oriunda tanto dos termos latinos como rixare, significando "brigar", ou resecare, "extirpar, suprimir", quanto do grego rhizikon ou, ainda, do árabe, risk. Muito cedo, na Itália, o termo designa "escolho", depois "naufrágio" e, em seguida, um perigo possível do qual o armador pode ser vítima. De fato, a palavra designa, ao mesmo tempo, tanto um perigo potencial quanto sua percepção, e indica uma situação percebida (VEYRET \& RICHEMOND, 2007, p. 25).
}

Partindo da citação exposta, percebe-se que a relação entre os conceitos de Risco e Perigo é bastante próxima. Menezes Júnior \& Silva (2016), ao apresentar os estudos elaborados por Marandola Jr. e Hogan nos anos de 2003 e 2004, referencia no seu artigo que:

O perigo está se confundindo com o hazards [risco - tradução nossa], sendo este definido por eventos naturais que desestabilizam um ciclo natural conhecido pela sociedade: terremotos, erupções vulcânicas, furacões etc. enquanto que o perigo se 
insere quando a população se torna suscetível a determinado evento por ter conhecimento da ocorrência. Logo, a sociedade estaria em perigo (MENEZES JÚNIOR \& SILVA, 2016, p. 15).

É uma proximidade conceitual que é diferenciada apenas pelo agente provocador e/ou de suscetibilidade. Para tal autor, portanto, Risco está associado aos eventos naturais que provocam o prejuízo, enquanto Perigo está posto num contexto social, associando-se, assim, ao fato do ser humano (e sua organização enquanto sociedade) estar suscetível (ou provocar) o evento de prejuízo. A própria Nações Unidas (ONU) corrobora essa visão conceitual ao apresentar a definição de risco como: "grado de pérdida previsto debido a un fenómeno natural determinado y en función tanto del peligro natural como de la vulnerabilidad” (Naciones Unidas, 1984, p. 80). Que, numa tradução livre nossa significa: (O) grau de perda esperada devido a um determinado fenômeno natural, em função tanto do risco natural quanto da vulnerabilidade.

Porém, quando se parte dessa ideia relacional, expõe-se o erro de desconsiderar o aspecto social como elemento de risco, tendo em vista o risco existir quando temos a sociedade representada no contexto do perigo. Dessa forma, como explicar, por exemplo, o risco social, ao qual famílias carentes, ou que não possuem condições de moradia e acesso a bens e serviços básicos que oportunizem melhores condições de enfrentamento, estão expostas? É possível excluir os elementos sociais de uma análise dos riscos e da exposição de pessoas e comunidades aos mesmos?

Entra em ênfase, portanto, a vulnerabilidade e a suscetibilidade como conceitos relacionados.

Para Carneiro e Veiga (2004), é a pobreza o elemento principal para uma maior exposição aos riscos, principalmente num contexto de ausência de proteção e seguridade social. Janczura (2012) complementa ao afirmar:

A ausência de recursos materiais alimentará outras fragilidades: baixa escolarização, condições precárias de saúde e de nutrição, moradias precárias em locais ambientalmente degradados e condições sanitárias inadequadas (necessidades insatisfeitas). Famílias e pessoas em tais condições de vida disporão de um repertório mais reduzido para enfrentar as adversidades (JANCZURA, 2012, p. $304)$.

Considerando-se, portanto, que o risco é a situação onde pessoas e/ou o meio ambiente está exposto à suscetibilidade de ocorrência do dano ou do evento prejudicial, levanta-se as seguintes observações:

- Seres humanos estão vulneráveis e suscetíveis ao risco enquanto o meio ambiente, dada suas condições físico-naturais, está suscetível à degradação, sendo as características sociais e/ou as 
condições físico-naturais, as variáveis (fatores) para determinação e mensuração dessa vulnerabilidade/suscetibilidade;

- A percepção de riscos consolida-se como uma estratégia metodológica, datada do início do século XX, cuja avaliação empírica dá-se por meio da construção de diferentes categorias de manifestação (SOUZA \& ZANELLA, 2009, pp. 29-30); e,

- O desastre é a consequência e/ou o efeito gerado num contexto de maior risco, resultante da consolidação prática da ameaça (perigo), caracterizada, necessariamente, como negativo.

Outrossim, no que tange o aspecto natural associado ao perigo, como desconsiderar os fenômenos naturais extremos que, ao consolidar-se, ameaçam a vida humana? Fenômenos naturais extremos são plenamente possíveis de ocorrer e a sua ocorrência, numa situação ou num espaço geográfico habitado por sociedades vulneráveis e/ou ambientes frágeis, consolida a existência do perigo à vida humana. Dessa forma, não se pode excluí-la (a ocorrência de eventos naturais extremos) do debate sobre perigo.

Um perigo natural é um fenômeno natural extremo que ameaça vidas humanas, atividades, bens ou o ambiente. Sua presença é constante ou está sujeita a flutuações. Muitos deles são cíclicos, como os tremores de terra associados à acumulação gradual de pressão sobre uma falha. Outros, especialmente os meteorológicos, tendem a ser sazonais. Fenômenos naturais podem ser transformados em perigo, quer por excesso quer por falta (LICCO \& SEO, 2013, pp. 4-5).

Assim, tanto os elementos de ordem natural e social contribuem para uma maior exposição aos riscos, bem como existência do perigo nos diversos contextos modernos. Dessa forma, a necessária ampliação dos conceitos de risco e perigo remete para uma sintetização dos mesmos, de forma que esteja próximo de uma definição que siga uma linha de raciocínio que considere a diversidade e a complexidade da realidade. Num contexto de sociedade contemporânea, risco e perigo estão muito próximos, porém não deve ser considerada a mesma coisa, estando o risco mais para a situação probabilística de ocorrência do evento indesejado, levando em consideração o quão vulnerável, suscetível ou exposto está o indivíduo, a comunidade e o elemento físico-natural.

A figura 1 se propõe a apresentar a interseção entre os conceitos perigo, exposição e vulnerabilidade, demonstrando que o termo risco está posto em todo o contexto da construção dos mesmos. Assim, nota-se que o desastre é resultado da confluência entre a exposição de uma sociedade vulnerável ao perigo, conforme observado. 


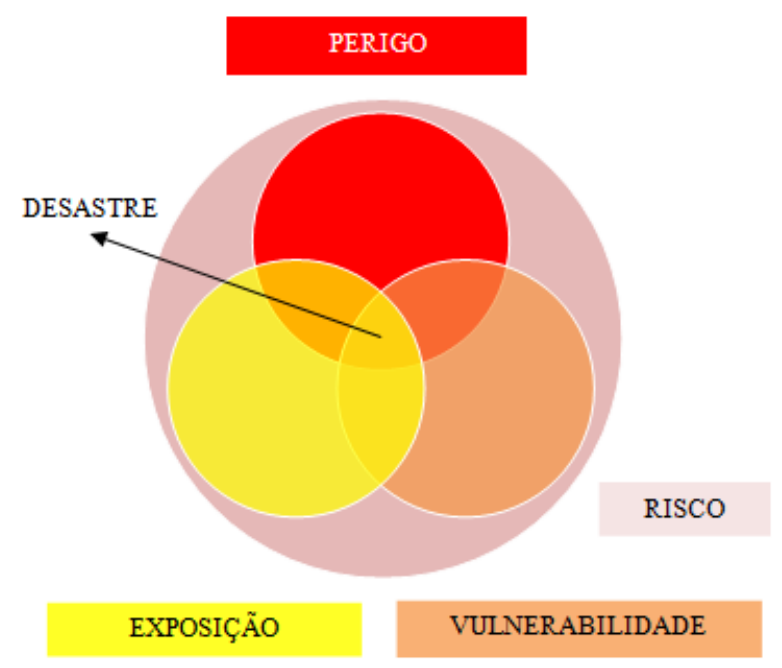

Figura 01. Diagrama de análise da relação entre Perigo, Exposição e Vulnerabilidade como elementos de interseção do desastre.a. Fonte: Adaptado de Licco \& Seo (2013, p.5).

Vulnerabilidade e fragilidade são conceitos inter-relacionais entendidos como sendo a condição ou característica que expõe o elemento/sujeito ao risco de ocorrência do evento indesejado (desastre, catástrofe, acidente, doença, degradação etc.), tornando-o suscetível. Em outras palavras, alguém está em condição de vulnerabilidade enquanto algo é/está suficientemente suscetível à onipresença do risco. Entende-se que quanto a isso, há um consenso, ou seja, é uma condição.

Zanella et al. (2009, p. 192) afirma que vulnerabilidade é uma noção multidimensional, que pode surgir em virtude de fenômenos múltiplos, a partir de causas distintas, gerando consequências diversas, afetando diferenciadamente os variados grupos sociais e/ou elementos naturais. A dimensão da interferência (efeito, que por sua entendemos ser o evento socioeconômico, sinistro, desastroso ou catastrófico) vai depender da estrutura socionatural do afetado, bem como da intensidade e características do perigo.

Entendemos que a existência de riscos associados às fragilidades e vulnerabilidades considera a necessidade da existência de, pelo menos, um dos fatores:

- Condições de vida da população e sua capacidade de resposta ao risco (vulnerabilidade social); - O uso e a ocupação irregular dos espaços e a fragilidade natural do ambiente (suscetibilidade ao risco);

- Condições físicas e fatores sociais interagindo de forma desordenada ou em desacordo com as normas de proteção ambiental e de seguridade sanitária (risco socioambiental).

Trabalhar com vulnerabilidades requer, enquanto primeiro passo, o entendimento do conceito, suas multifacetas e interpretações, na perspectiva de construção de um caminho 
consensual para sua definição. Assim, a vulnerabilidade pode assumir condições de alteração do meio ambiente, da sociedade e de ambos. O conceito de vulnerabilidade acaba por contemplar uma visão holística de todos os fatores associados ao risco e ao desastre.

Em suma, num cenário de vulnerabilidade determinado, o potencial de perigo pode ser mensurado com vistas à identificação das situações de exposição ao risco. Esse mesmo potencial de perigo pode ser reduzido ou não, conforme se caracteriza o cenário (condições físico-naturais, sociais ou econômicas), reduzindo ou aumentando o risco.

A figura 2 mostra uma síntese dos conceitos principais apresentados, bem como a relação entre eles.

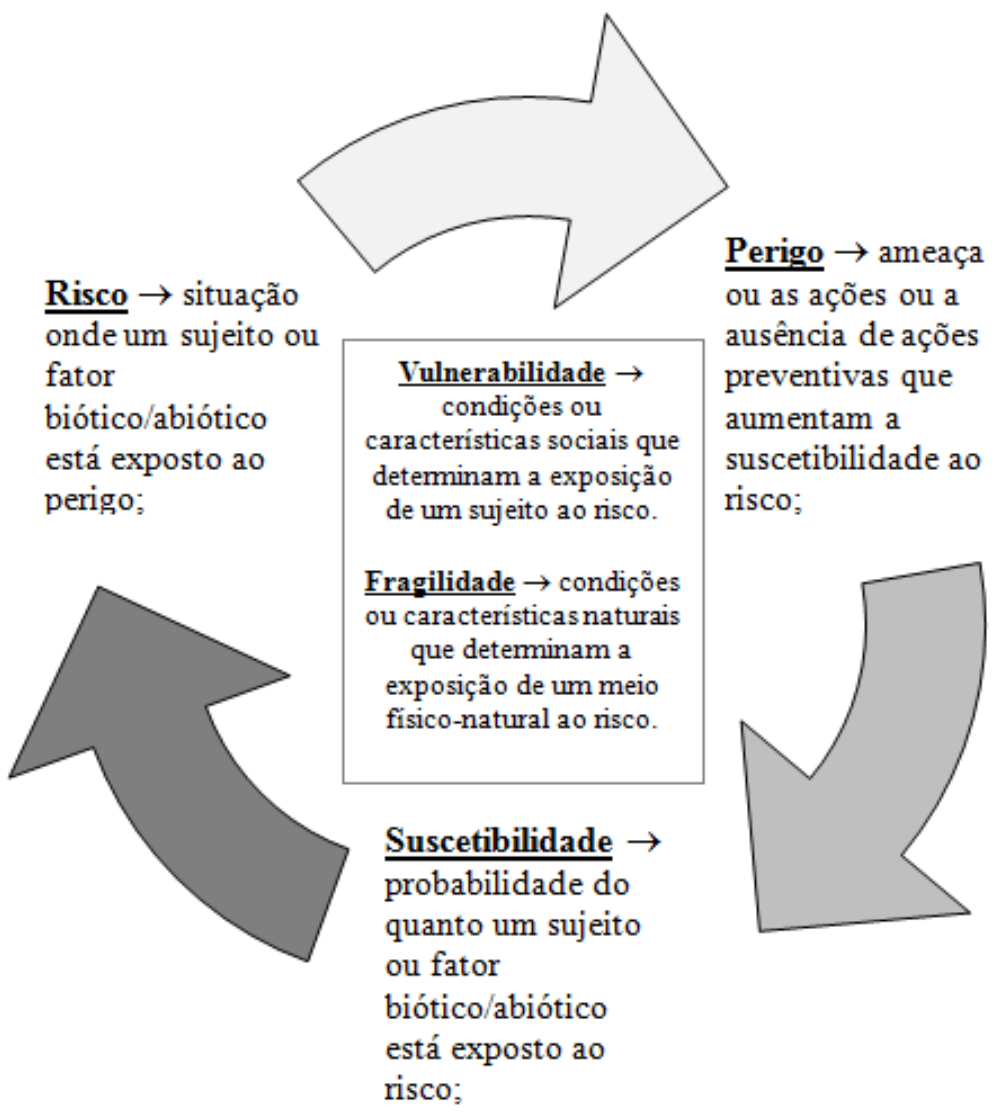

Figura 02. Diagrama de apresentação da síntese dos conceitos de Risco, Perigo, Vulnerabilidade e Suscetibilidade. Fonte: próprio autor (2016).

Por exemplo, uma área de acentuada declividade caracteriza-se como o cenário de suscetibilidade que vai ser determinado de acordo com suas características de solo, de cobertura florestal, de grau de declividade, etc., majorada pelas condições de uso e ocupação da área. Conforme ocorre o desmatamento, ou substituição da vegetação primária, ou mesmo ocupação da área por habitações, estabelece-se a ameaça de ocorrência de fatores variados como perda da qualidade ambiental, deslizamento, morte etc., todos estes caracterizados como danos, ou 
tragédias, ou mesmo eventos indesejados. O Risco será, portanto, a situação resultante da relação entre a área de declividade e as exposições às ameaças geradas pela intervenção. Como efeito, a população que habita o local está vulnerável.

$\mathrm{Na}$ figura 3 visualizam-se cenários diferentes, conforme descrito anteriormente, referentes ao mesmo espaço geográfico. A diferença está na efetiva modificação transformação do espaço a partir do uso e ocupação pela sociedade, o que gera modelos ambientais alterados e acentua condições de suscetibilidade.

As ocorrências naturais de movimento de massa em regiões de altas declividades, caracterizando a fragilidade do ambiente físico-natural, são aceleradas ou acentuadas pela ação antrópica. Tais transformações provocam alterações funcionais e geomorfológicas, fomentando a condição de suscetibilidade, consolidando o Perigo. Uma vulnerabilidade elevada propõe cenários piorados de capacidade de resposta da sociedade afetada. Essa, estando mais exposta ao risco devido à alteração provocada, está suscetível ao desastre, considerada como a efetivação do efeito adverso indesejado e prejudicial.
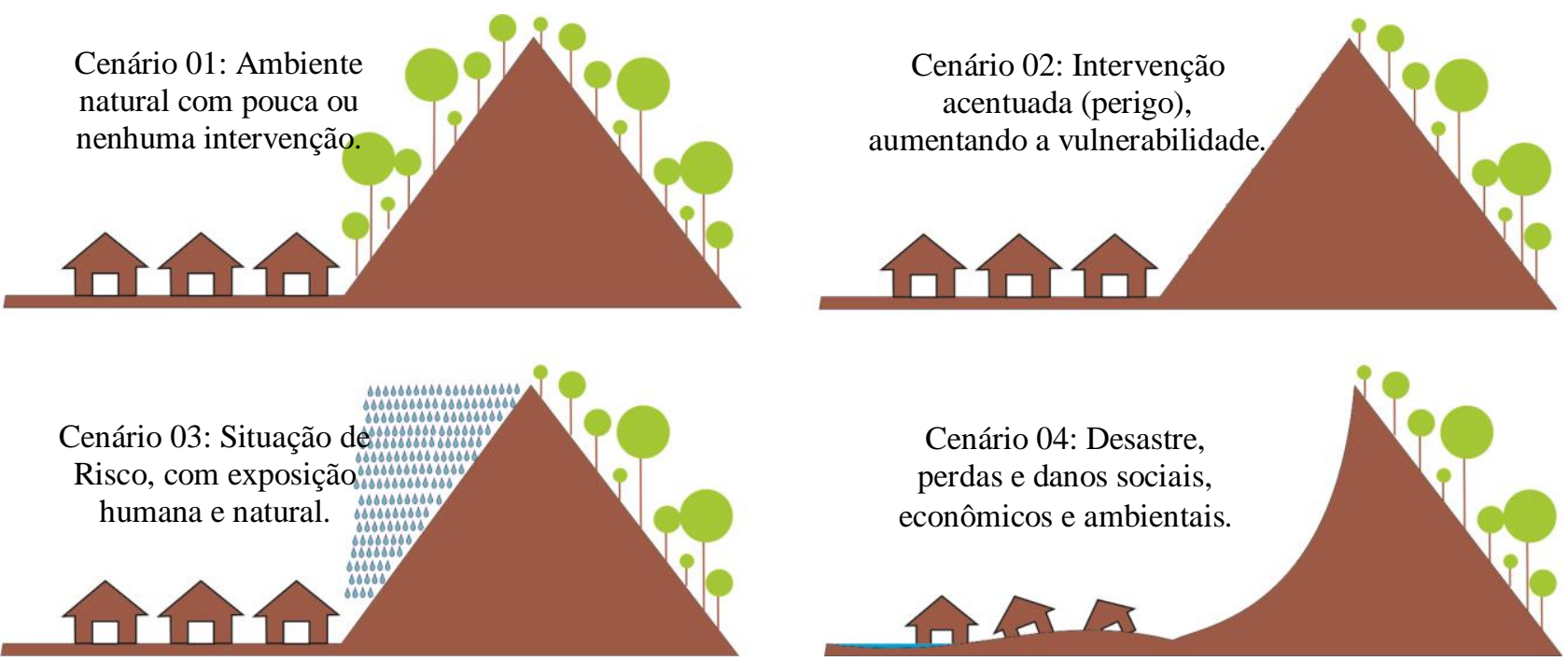

Figura 03: Representação gráfica dos cenários descritos. Fonte: próprio autor, 2017.

Na figura 4 visualiza-se uma condição de substituição de vegetação primária protetora de encostas por monocultura de banana caracterizando-se como uma ameaça geradora de Risco de solifluxão. Na figura 5 a fotografia apresenta um evento de solifluxão, ocasionado pela relação entre excesso de pluviosidade e substituição da vegetação primária por monocultura de banana, efetivando o risco de deslizamento. 


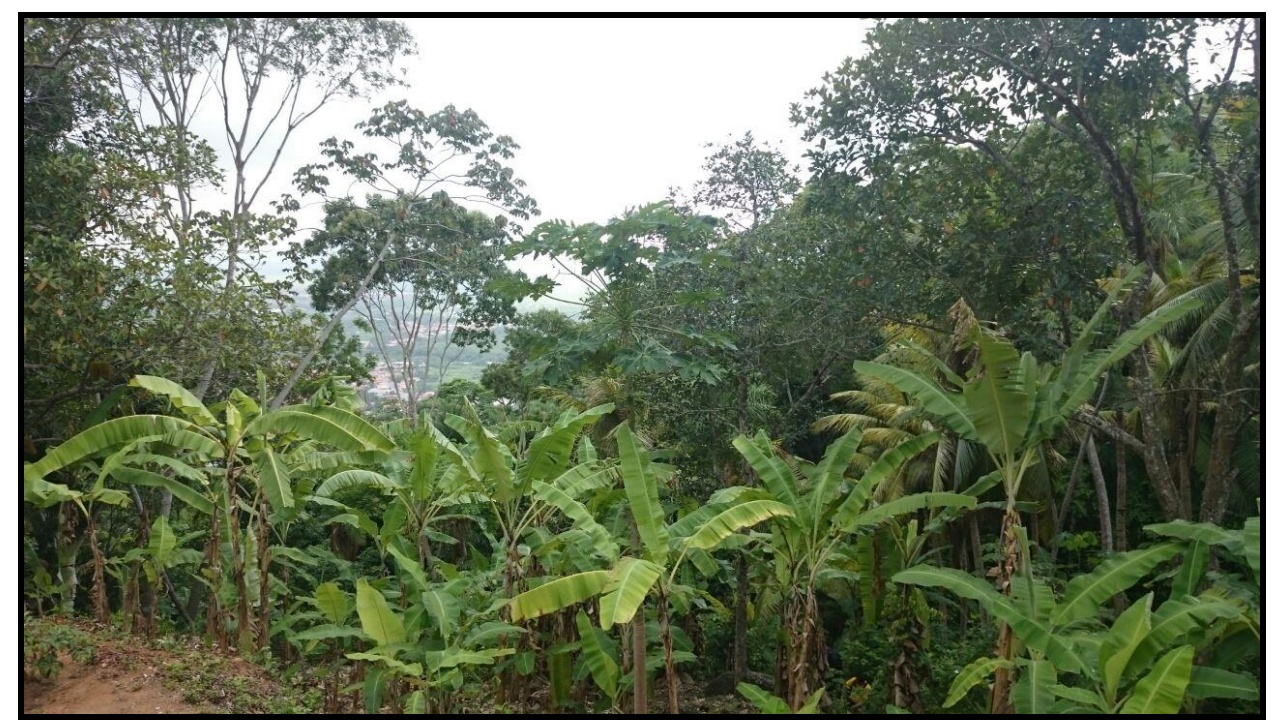

Figura 04: Fotografia ilustrativa da substituição de vegetação nativa por monocultura da banana. Fonte: próprio autor, 2015.

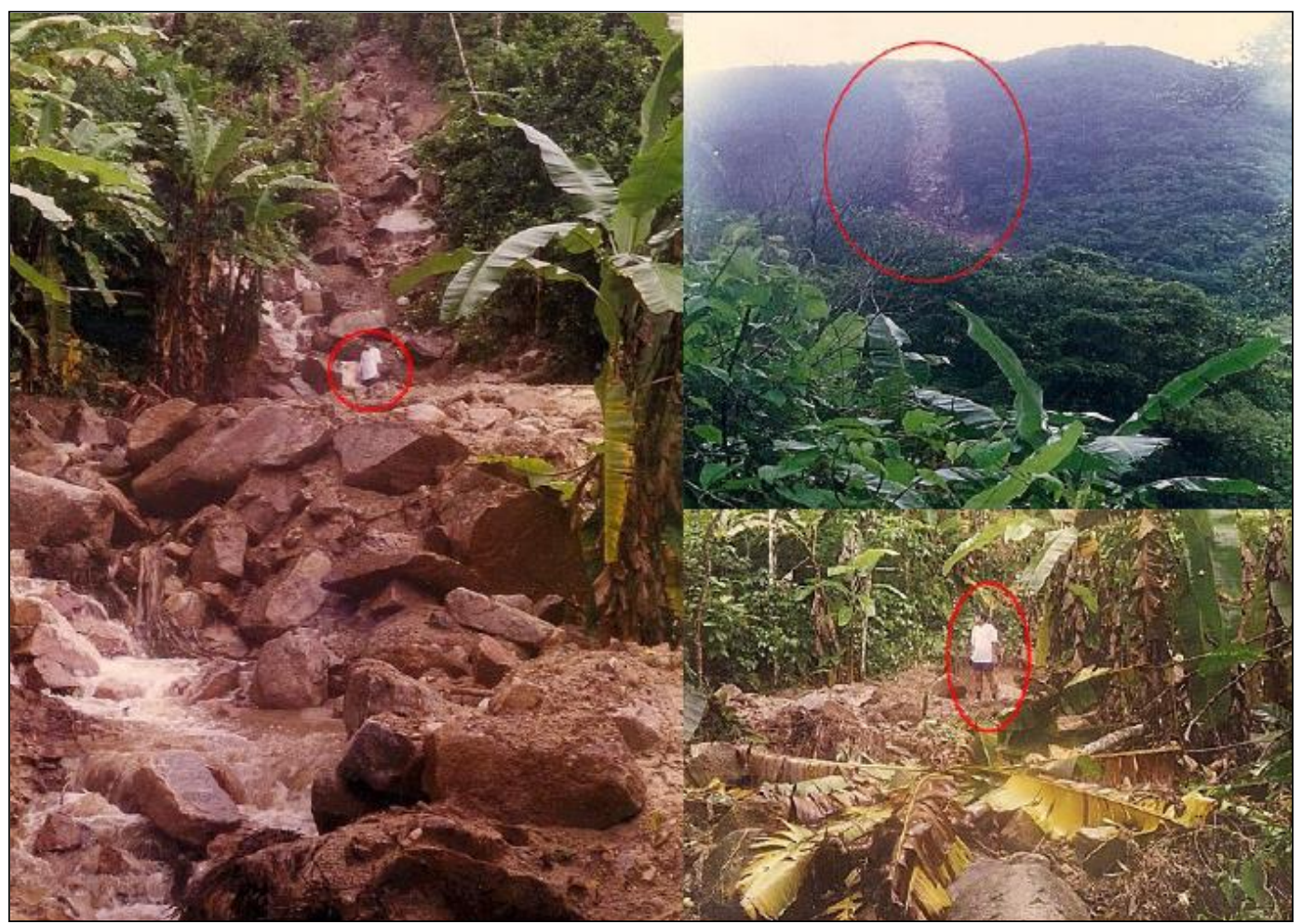

Figura 05: Fotografia de um evento de solifluxão. Fonte: CORDEIRO et al., 2014, p. 147

Dessa forma, consolida-se a hipótese em torno da afirmação de que o uso e a ocupação inadequado do solo provoca a existência de áreas de maior exposição aos riscos por meio da intensificação da fragilidade físico-natural, gerando suscetibilidade. A vulnerabilidade fomenta tudo isso, especialmente se considerarmos as condições de capacidade de resposta ao perigo pela sociedade. 


\section{CONSIDERAÇÕES FINAIS}

O cenário contemporâneo aponta para uma transformação cada vez mais intensa da natureza, pelo ser humano. Tais transformações, motivadas pela necessidade de adaptação, pelo consumo e pelo avanço tecnológico, que requer o uso de recursos naturais, tem modificado significativamente a natureza, provocando alterações nas características próprias da mesma. Ademais, cada componente físico-natural possui sua particularidade e complexidade, o que confere a cada ambiente um grau de resiliência próprio às mudanças ambientais.

Considera-se, portanto, que a vulnerabilidade humana e a suscetibilidade físico-natural estão postas nas situações em que tanto um quanto outro estão prejudicados. Ou seja, quando uma perturbação é provocada de tal forma que resulta em efeitos adversos, especialmente, ao meio ambiente e a sociedade impactada, gerando suscetibilidade ao risco. Dessa forma, concluise que o risco posta-se quando a sociedade é afetada, efetivando um cenário de perigo à saúde, segurança, bem-estar, etc. O termo socioambiental, frente a relação sociedade-natureza, revela-se como uma abordagem contemporânea para compreender os desafios da questão ambiental consolidados.

\section{REFERÊNCIAS}

AUGuSto FiLHO, O. Carta de Risco de Escorregamentos Quantificada em Ambiente de SIG como Subsídio para Planos de Seguro em Áreas Urbanas: um ensaio em Caraguatatuba (SP). 2001. Tese (Doutorado em Geociências e Meio Ambiente) - Instituto de Geociências e Ciências Exatas, Universidade Estadual Paulista Júlio de Mesquita Filho, Rio Claro, 2001.

AURÉLIO. Dicionário Aurélio Online. Disponível em: https://dicionariodoaurelio.com/risco. Acesso em: 22 de out de 2016, às 19h12.

JANCZURA, Rosane. Risco ou vulnerabilidade social? Textos \& Contextos, Porto Alegre, v. 11, n. 2, p. 301 - 308, ago./dez. 2012.

LICCO, Eduardo Antonio; SEO, Emilia Satoshi Miyamaru. Perigos e riscos naturais: estudo de caso do Jardim Pantanal. Revista Interfaces. Vol. 8, n. 1, 2013. ISSN 1980-0894.

MENEZES JÚNIOR, E. M.; SILVA, O. G. da. Diferentes percepções para a compreensão do conceito de risco no enfoque ambiental. Revista Casa da Geografia de Sobral. v. 17, n. 2. p. 12-22. Jul. 2015.

NACIONES UNIDAS. Dpto. de Asuntos Humanitarios, DHA. Prevención y mitigación de desastres. N. York, UNDRO, 1984, Volumen 10. 145 pp. 
SANTOS, J. de O. Relações entre fragilidade ambiental e vulnerabilidade social na susceptibilidade aos riscos. Revista Mercator. Fortaleza, v. 14, n. 2, p. 75-90, mai./ago. 2015.

SOUZA, L. B. e; ZANELlA, M. E.. Percepção de Riscos Ambientais: Teoria e Aplicações. $2^{\text {a }}$ Ed. Fortaleza: Edições UC, 2010. 240 p.

TRICART, J. Ecodinâmica. Rio de Janeiro: IBGE, 1977.

VEYRET, Yvette (Org.). Os riscos: o homem como agressor e vítima do meio ambiente. Trad. Dilson Ferreira. São Paulo: Contexto, 2007.

VEYRET, Y.; RICHEMOND, N. M. "O risco, o risco: Definições e vulnerabilidades do risco". In: VEYRET, Yvette (Org.). Os riscos: o homem como agressor e vítima do meio ambiente. Trad. Dilson Ferreira. São Paulo: Contexto, 2007. 23-80.

ZANELlA, M. E.; DANTAS, E. W. C.; OLÍMPIO, J. L. S. A Vulnerabilidade natural e ambiental do município de Fortaleza/CE. Boletim Goiano de Geografia. Goiânia, v. 31, n. 2, p. 13-27, 2011.

ZANELLA, M. E.; OLÍMPIO, J. L.; COSTA, M. C. L.; DANTAS, E. W. C. Vulnerabilidade socioambiental do baixo curso da bacia hidrográfica do Rio Cocó, Fortaleza-CE. Sociedade \& Natureza. Uberlândia, v. 25 n. 2, p. 317-332, mai. 2013.

\section{AGRADECIMENTOS}

Nossa gratidão ao programa de Pós-Graduação em Desenvolvimento e Meio Ambiente da Universidade Federal do Ceará e ao Departamento de Geografia da mesma universidade.

Recebido em: 08/12/2017

Aceito para publicação em: 10/05/2018 